\title{
No Repitamos a Europa, Americanos
}

$F^{\text {RENTE a los acontecimientos del mundo en estos años de tu- }}$ multuosas olas de violencia, incomprensión y desconfianza, un mensaje apropiado y oportuno para los hombres de América entiendo que podría enunciarse en esta fórmula sucinta: - No repitamos a Europa, americanos.

¿Cómo será ello posible? ¿No encierra, fórmula tal, una presuntuosa declaración de independencia, y en cierto modo de superioridad sin prueba sobre nuestros maestros, sobre los formadores de nuestra alma y de nuestra cultura? A eso vamos.

Que es posible no repetir a Europa, me parece que fluye de la demostración de lo necesario que es no repetirla, siempre y en tanto que deslindemos y delimitemos el postulado. Harto pesan sobre los hombros de América cuatro siglos de reproducción constante, de copia continua, de calco minucioso de cuanto Europa ha sido o pretendido ser, y no se olvide que en toda reproducción, copia o calco se desliza siempre un ineludible elemento de deformación. Se nos tacha, y con verdad, del prurito imitador que nos ha conducido al desposeimiento de nuestra alma verdadera, a ser infieles con nosotros mismos. Imitamos en literatura como en política, en modas suntuarias como en estilos artísticos: es superfluo, ante el buen entendedor, exponer el abundoso inventario de nuestras imitaciones; en lo más ordinario de la vida como en lo más refinado de sus expresiones, hallaremos, puntualmente, el testimonio que se quiera de esa dolencia nuestra.

Esta dolencia nuestra nos ha granjeado en Europa, a partir del siglo pasado, una reputación poco agradable, para calificarla discretamente; la soberbia europea de su época cosmopolita de florecimiento -y decadencia - se solazó frecuentísimamente en apellidarnos con motes desdorosos que, si ultrajaban nuestro naciente orgullo, no de- 
jaban de entrañar una raíz de exactitud penosa, pero carecían de virtud bastante para hacernos reflexionar y reaccionar en debido aleccionamiento: protestas aisladas, a veces también vocingleras en demasía y de poco fondo, respondían a esas alusiones ingratas, y seguíamos perpetuamente de hinojos recibiendo el deslumbramiento de Europa, pagándole un tributo inmemorial que se traducía por parejo en libras esterlinas y en admiraciones hiperbólicas no sólo a cuanto las acreditaba por su intrínseco y ostensible valor - i y era tanto!--, sino a las más triviales manifestaciones del saber o del ingenio europeos.

Metecos, rastacueros, indianos, continente estúpido o continente ingenuo: de todo se nos llamó, y soportábamos con paciencia, y sonriendo por venir de tan superiores labios, las invectivas irónicas y amargas con que se hablaba por ejemplo de nuestras pequeñas repúblicas balcanizadas y de nuestra pintoresca barbarie. Era eso, a pesar de su rigor, parte de nuestro aprendizaje, precio oneroso de nuestro crecimiento. Faltos de un pasado profundo, pues por igual nos eran íntimamente extraños los pasados aborigen y europeo que confluían en nuestra realidad espiritual y con imán dispar nos solicitaban, y educados bajo el preponderante dominio europeo y el menosprecio de lo indígena, ennegrecido rencorosamente el recuerdo colonial, hijos tardíos del Renacimiento, tuvimos que aclimatar nuestra alma, cuando tomamos posesión de la tierra americana ya por propia cuenta en las postrimerías del setecientos y los albores del ochocientos, en el lecho de la cultura europea, que alcanzaba por entonces sus más erguidas cumbres, provista de férreas alas por el progreso, el progreso, la deidad del nuevo siglo, que sucedía al reinado efímero de'la efímera Diosa Razón.

Fué, claro, bien impagable que así haya sucedido: sólo hijos espurios o contrahechos pueden desear padres diferentes, a su capricho. $Y$ en América, sin duda, empezó a desarrollarse aquella cultura, sobre la ancha base cristiana que nos dejó la colonia, con matices imprevistos, que pudieron y debieron acentuarse mejor, si dos graves fenómenos no se interponen en su camino; los hasta ayer inacabables disturbios de las revoluciones alternadas de regresivas o estacionarias dictaduras en las más de nuestras repúblicas, y que por lo relativo a Hispanoamérica contribuyeron tanto a demorar el progreso $\mathrm{y}$ a remarcar la desigualdad entre el opulento y práctico Norte anglosajón y el indolente y soñador Sur indoibérico, y la fuerza de seduc- 
ción con que nos atrajo Europa, que así nos reconquistaba con más sutil imperio, fracasadas sus armas, escolladas sus santas alianzas ante la voluntad de independencia - curiosa pero explicablemente aún no espiritual - que en el cerro de Las Campanas adquirió, en símbolo sangriento, la más dramática elocuencia. Europa nos atrajo con sus exposiciones, sus libros, sus doctrinas libertarias, su hervor social, sus laboratorios, sus novedades, sus modas, y allá fuimos en incesantes peregrinaciones estudiantes y políticos, periodistas y millonarios: llegó a no concebirse cultura en los americanos que no fueran a obtener su consabido barniz de europeísmo - a costa de mil renuncias, esta vez de humillaciones, la otra de artificios, y a costa del oro de las fincas, de las fábricas y de las arcas públicas-, y bastaba haber noctambuleado por bulevares parisinos, conocido por fuera muros de Oxford o Heidelberg o bogado por canales de Venecia para regresar - dichosa fatuidad americana - con triunfales preseas y la estatura subida muchos codos sobre cuantos suspiraban por el no realizado viaje. Mas éstos no repudiaban su sueño, corporizándolo en estudios franceses y alemanes los profesionales; lecturas francesas, rusas de segunda mano y cada vez menos españolas los literatos; en modas inglesas y francesas las damas y los elegantes; en casas y ajuares copiados o traidos de Europa los pudientes, en una saturación general de europeísmo, no siempre al día, es cierto, pero siempre sentido como una segunda e imperiosa naturaleza.

Sería injusticia negar que esa apetencia de lo europeo produjo bienes, cierta elevación del tono de la vida, cierto gusto que superaba la mediocridad ambiente, aunque también estimulaba las vanidades y las arrogancias a que hay en el alma americana una siempre despierta propensión. Mas es verdad asimismo que esa adoración tan mal correspondida enajenaba comarcas enteras de nuestro ser y restaba a su desenvolvimiento auténtico, por encontrar todas las soluciones hechas, posibilidades irrecuperables. Por este fanatismo persistimos, independientes y soberanos si separados en la inmensidad de nuestra tierra sofocada de distancias, bajo un régimen de colonialidad chocante, que los propios europeos eran los primeros en señalar con un amplificador acento circunflejo de sorpresa e ironía y que aún recientemente, perspicaces viajeros del linaje de los Keyserling y los Siegfried subrayaron en categóricas comprobaciones e irrebatibles testimonios en los terrenos de la economía y la técnica como en los reinos del espíritu: que tan profundo caló en sus efectos retarda- 
tarios - pues los otros eran más superficiales, más de exterioridadla europeización de nuestra vida, pensamiento y costumbres.

La conflagración del año 14 abrió un enorme calderón en el proceso seguido. Europa se desquició en la crisis bélica y en sus secuelas, la crisis económica, y, lo más tremendo, la crisis moral, precursoras, para Berdiaeff, de la aurora de una nueva edad media. El sueño cosmopolita de Europa se derrumbó; el socialismo internacionalista vió por el suelo sus columnas más recias; se desplazó, junto al espectro del oro, el eje de la cultura, imperceptiblemente todavía, hacia el nuevo mundo, por el extremo más avanzado y, por afinidad, más europeo, el Norte atlántico. Pero aquella conflagración —en que participamos aunque a título de caudatarios, seducidos por el tremolar de los últimos estandartes gloriosos de Europa: la libertad, la justicia, el derecho-, constituyó también una embriaguez de europeísmo en que pudieron disfrutar ya hasta nuevas clases sociales de americanos, porque Europa se puso al alcance de todas las fortunas y la publicidad beligerante, dueña de nuevos medios y de recursos fabulosos no conocidos antes, fustigó con sus centellas todas las almas. En pie de igualdad ficticia, en el fugaz jubileo de la confraternidad, nos sentamos en el que quiso ser ecuménico anfiteatro de las naciones: con recónditas reservas de familia marchita en sus timbres nobiliarios, Europa hubo de resignarse a acoger en su seno - sí, esto fué-, y como a pares, a los recién venidos a la vida plena, vigorosos de salud que la mortificaba, bulliciosos de juvenil insensatez todavía y con las maneras no afinadas lo bastante como para no singularizarse en los penumbrosos salones llenos de antiguos perfumes y de solemnes antiguallas.

El nuevo sueño desvanecióse tan en breve como había construído sus intangibles castillos. Aparecieron, dominantes, agresivos desde su huevo natal - la guerra--, las ideologias de fuerza y preeminencia, y las eternas madejas de intrigas, de indecisiones, de veleidades, de la política y la diplomacia en cuyo cultivo ha envejecido Europa; era imposible - lo demostró hasta el dolor la fallida esperanza española- que Europa se renovara en la aceptación de la democracia y el ejercicio de la paz orgánica: por todas partes bullía amenazante la guerra; por todas partes estallaba la violencia; por todas partes se condensaba el odio; por todas, la venganza asomaba cárdena, lívida, la desventurada faz. De la miseria se hacían armas; de las privaciones se hacian armas. Como dogma coronábase la estatolatría. ¿De 
qué servían tanta cultura, tanta acumulada sabiduría, tanto esplendor universitario, tanto recuerdo de superpuestas civilizaciones, tantos progresos materiales y tantas magnificencias que se sintetizaban en el nombre legendario de Europa?

Lo que la guerra no destruyó, lo que no alcanzó con sus manos voraces de incendio y ruina, era minado por sigilosas maniobras de nacionalismos egoístas y ambiciosos que, sin recato, asaltaron el poder y envenenaron las almas. Hasta las naciones más queridas para el americano, replegáronse en la pasión y secreta o abiertamente declararon su designio de dominar, y las mismas que no asumieron puesto de primera fila en la batalla de los nacionalismos, se dejaron contaminar por las especiosas propagandas y sintieron el hechizo de los nuevos órdenes o se dividieron, para su mal y el de la humanidad, en facciones rencorosas que prepararon la entrega y la derrota. $O$ se cobijaron en el temor y el espanto, amedrentadas, acorraladas, exagerando su debilidad.

¿Qué más! Si América misma, nuestra América, salida de las forjas democráticas tras una lucha constelada de heroísmos y bizarrías, América donada a la humanidad en el pensamiento de sus mejores, experimentó el contagio en más de una de sus aviesas modalidades. Esto era natural, forzoso, sí, por los cauces mantenidos del viejo europeísmo; pero era ceguera no advertir que había llegado el instante de tomar responsabilidad de la propia vida y del propio mundo, para realizar el propio destino, que era ya, si antes no lo fuera, distinto del amargo destino de la Europa en declive. Era ceguera no comprender que se estaba en el momento de la mayoría de edad y en la encrucijada más dramática de la historia. Era ceguera no reconocer la urgencia de optar a la nueva autonomía e inclinarse a la necesidad de romper con antiguos lazos y hasta sacrificar viejos principios para recibir la dádiva del porvenir con limpias y seguras manos viriles.

Pero, en fin, América ha comenzado a ver más claro, y en las conciencias vigilantes lo que era desazón y desaliento empieza a convertirse en inquietud de otra clase, porque deber y sino de las conciencias vigilantes es no descansar tras ninguna conquista y desconfiar de todo buten suceso, adelantándose perennemente hacia sus apostaderos de atalaya, para renovar su ansiedad de futuro y cumplir con la grave misión de dar avisos a tiempo sin importar que quienes los perciben los trasmitan a su vez o no, con celeridad y eficacia, y sin 
importar que, tantas veces, se les reciba con aspereza y desabrimiento cual augurios funestos o reclamos irritantes que abochornan acusando imprevisiones, blanduras y dejadeces.

América ha comenzado a ver más claro. Pero está el horizonte tan lleno de siniestras humaredas y de tan sangrientas rachas, y hay en el mundo tal estruendo y desasosiego, que los mejores ojos y los más aguzados oídos no escapan al peligro de confusión y torpeza. No en todo momento y a despecho de delicados detectores, puede saberse si los aviones que pasan son portadores de la muerte, o los amigos y guardianes de nuestro hogar. No se sabe en todo momento si las palabras expresan su sentido puro y solo, o guardan venenosa capciosidad, ponzoñosa insidia en la negra entraña, que a tal punto ha prosperado la obra de los cultivadores del mal y la desconfianza en el mundo. $\mathrm{Y}$, sin embargo, con estar rodeados de enemigos y avistados de asechanzas por dondequiera, son más fuertes y más audaces nuestros enemigos internos, los que brotan a veces de nuestra misma conciencia, enmascarados, y porfían por inducirnos en error de credulidad, de violencia, de descorazonamiento o de duda, en error de lo opuesto a aquello que habemos menester.

Estos enemigos deben ser batidos sin compasión; estos enemigos reclaman toda la energía de nuestra capacidad guerrera. Necesitamos sobreponer a los elementos de desorden los elementos de estabilidad y de rectitud; necesitamos enjuiciar los errores ajenos en el mismo plano y con la misma severidad que los errores propios; necesitamos desentendernos de viejas utopías y tomar contacto con todas las realidades de hoy, para preparar el futuro en esa parte en que el hombre puede hacerlo, pero no vivir más con la obsesión del futuro como entelequia, del futuro como si tal tiempo fuese a ser nuestro en absoluto, a ser mejor por el sólo hecho de ser futuro, y a estar exento, por insospechada magia, de sinsabores, de oprobios, de caílas, de desgarramientos: por el contrario, deberíamos pensar en un porvenir dificil, para lo cual nos prepara, instruye y amonesta la experiencia de siglos: conforme aumentan los instrumentos de satisfacción de necesidades y alegrías, conforme se avanza en la senda del progreso colmada de sorpresas y de señuelos de comodidad y bienestar, la humanidad encuentra - es la enseñanza constante del pasado- nuevos motivos de inquietud y descontento, trabajos mayores, empresas más arduas que exigen creciente dosis de esfuerzo, desen- 
gaños impensados y fatigas inimaginadas, y esto, que parece un desanimador contrasentido, es la original esencia de la civilización, el impulso poderoso de la elevación espiritual del hombre, insatisfecho siempre, no saciado nunca, dichoso jamás. $Y$ enhorabuena, pues si no la existencia carecería de sentido y de importancia, en desnuda inanidad.

Prepararnos para ese futuro, significa hacer cuentas claras de nuestras posibilidades, de nuestros recursos y de nuestras aspiraciones. Como principio de esta basamental tarea se presenta desafiante el ejemplo de lo hecho en Europa como mundo viejo trabajado por todas las corrientes psíquicas e intelectuales, mundo que hemos tenido como ejemplo delante y como ideal cuando nuestra visión era más angosta, más limitada por nuestra incipiencia vital y por el empequenecimiento que sufriamos al reconocernos desprovistos, puede decirse, de historia y tradición, y bajo el sortilegio de lo europeo. El menos sereno juicio falla en contra de una repetición de Europa: Europa debe ser un modelo, un canon, respetado, alabado - admiración de museo y de texto de historia- pero no seguido. Como en arte se incurre en frío academismo y en infructuoso amaneramiento al repasar incesantemente formas y modos cuya virtualidad se ha evaporado con el tiempo en que tuvieron razón de ser y raiz profunda de originalidad sustancial, de virginidad de descubrimiento, las formas de la vida, la política, la acción, la filosofía, grande o inerte, de la existencia de un mundo, de una era, no deben repetirse; hay que librarse de la tentación de repetirlas cediendo a la ley de menor esfuerzo, por un esfuerzo supremo de voluntad y clarividencia.

Si nos está negado el dar a la vida nueva un sello de sólida personalidad y grandeza - lo cual en el caso americano está por probar-, de subvertir los órdenes y crear de la nada nuestros sueños, impongámonos el deber de continuar la carrera emprendida, sin mirar atrás como no sea para darnos cuenta precisa del avance, y tomando como punto de veloz partida ése donde Europa queda estancada en sangre y llanto y en que nosotros, americanos, merodeamos aún con una suerte de deleite insano o con una suerte de vacilación peligrosa. Afirmemos nuestro ser; consolidemos nuestros valores; desechemos lo superfluo, lo nebuloso y lo trivial de nuestra naturaleza y de nuestra sucinta historia, y dejemos de sentir la época que cruzamos como una "hora de prueba", como una transición, como un eclipse, porque estar pensando en esto significa inseguridad, significa que esperamos 
el paso de la tormenta para enhebrar tranquilamente los hábitos y las facilidades que perdimos un instante - los modelos hechos-, como si la vida pudiera reconstruirse sobre sus despojos, cuando lo que pide es creación jubilosa, aportaciones nuevas, ímpetus decididos. Digamos adiós sin conjoga al mundo antiguo, a la Europa que nos amamantó, como ciertas madres complacientes, hasta avanzada infancia y nos confirió todos sus bienes - y todos sus males- sin discriminación.

Pero, ¿̇ no es presuntuoso este afán de abandonar las normas tan apegadamente seguidas, los moldes tan orientalmente copiados? En verdad, tal parece cuando se habla de la ruina de la cultura europea, de la anulación y desahucio de Europa, ignorando el hecho sustantivo de que somos ya una Europa nueva, pero que debemos ser, y ahí reside el propósito cardinal, una Europa — vale decir un mundodiversa. No es presuntuoso, porque poseemos ya los elementos principales, venidos muchos de ellos de la propia Europa en busca de refugio y libertad, y esos elementos se aúnan a riquezas visibles y potenciales de toda especie, que el caduco continente no posee en modo alguno; pero a más de esto, tenemos elementos conexivos y unificadores superiores a cualesquiera que pueda alegar Europa y que para la gran tarea de nuestro porvenir son los de más apremiante atención y esperanza. Y, por último, ¿ la sola experiencia de Europa, bien reflexionada, no bastaría?

En la gran tarea de no repetir a Europa, sino de llevar adelante sus aciertos y sumir muy atrás sus errores y desatinos, tendrán participación prominente los elementos unificadores de nuestro hemisferio, y son éstos los que estaban padeciendo merma por la imitación desaforada y la contaminación de los apasionamientos europeos, de la demencia europea. América ha sido crisol de razas y debe serlo en una proporción mucho más vasta en lo sucesivo; América ha sido tierra de libertad para el hombre, y debe serlo de una manera más digna aún; América debe repudiar las restricciones de los nacionalismos de corta vista y sustituir al concepto limitado del particularismo con el generoso concepto de la americanidad como etapa, solamente, de transición en el tiempo hacia una edad en que en la tierra puedan imperar la concordia y la fraternidad sin riesgos ni reservas, en toda su haz. $\mathrm{Y}$ mientras esto sea dable, que las armas de América no forjen potencias, potencialmente agtesoras para mañana, no atribuyan preeminencias ni respalden "hechos consumados", 
en sus países, sino consorcios de defensa y seguridad, interna y continental, y que si azares imprevisibles originan y caldean la violencia un día y esas armas quisieran volverse hacia el costado de un hermano, estén prontas todas las fuerzas, todas las voces de la americanidad para reprimir la rebelión de los instintos primarios y mantener a débiles y poderosos en igual disfrute del derecho bajo una firme y respetuosa cordialidad. Porque, por desgracia, no podemos ocultar inconfeso el temor de que el crecimiento progresivo -en población, en industrias, en riquezas, en orgullo- de nuestros pueblos, en que un siglo de independencia ha marcado ya desigualdades y diferencias notorias, complique y enturbie un día las relaciones interamericanas por cualquier rumbo del horizonte, o bien que por labor de instigadores, que no faltarán, resurjan o puedan resurgir olvidados conflictos o se les cree nuevos a medida de siniestros fines: para una eventualidad semejante, y ojalá no brote jamás como excrecencia de nuestra nueva historia, hay que prepararse también: cada pueblo, todos los pueblos de América, deberán estar despiertos, alertas, y apercibidos a cualquier llamada de su destino. ¿Y quién sabe el tono de voz, el apremio y la hora en que el destino haya de llamarnos?

Una duda adicional, pero demasiado fuerte para omitirla aun en cuadro tan incompleto y somero como éste: ¿ puede construirse un porvenir conscientemente? Ya se deslizó por ahí la respuesta negativa circunscribiendo a mínima órbita el influjo de la voluntad racional para tamaña empresa. "En la vida histórica de la humanidad, lo que se realiza no es jamás lo que el hombre se había propuesto como finalidad - expresa Berdiaeff-. Pero sin que él mismo se dé cuenta, se crean enormes valores que él no había jamás previsto." Ahora bien: tratándose del porvenir de una nación y de un grupo de naciones reunidas bajo la acción de tantos elementos unificadores y cooperantes como en el caso de América, existen hartas circunstancias favorables que aprovechar para cimentar esa estructura del porvenir que nuestros hijos y sus hijos irán haciendo y rehaciendo sin fin, con máximas posibilidades de excelencia, y a ello debe tender el aliento americano, a ello debe acudir la conciencia de la americanidad, aleccionada en los desastres de Europa, depurada, sin vanidad y, más justamente, preocupada del buen empleo de sus fuerzas y de la curación de sus flaquezas, tomando respaldos seguros contra riesgos y accidentes, bajo el lema de no repetir a Europa, de superar su cultura y dignificar su conducta. 
Temible es, empero, el riesgo que corremos en la insigne aventura por incurables - porque hasta hoy nadie rigurosamente se ha curado de ellos- vicios de nuestra idiosincracia: a los americanos todo se nos vuelve tópico o polémica, pretexto de vocinglería o motivo de vociferación, y será desdicha suma que en esta hora, tremenda como ninguna pero como ninguna propicia para acrisolar virtudes y victorias, to reduzcamos todo a palabras, a divagaciones $\mathrm{y}$ ensueños o bien a controversias vanas, cuando toda la energía está embargada por la lucha para vencer al mal, y para la simultánea acción para reconstruir lo que se quiere, lo que debe ser.

Hace más de ciento cincuenta años, es decir, más años que los vividos independientemente por nuestra ahora apaciguada y al parecer más seria América hispánica, trece colonias que se equipararon a otras tantas estrellas y se multiplicaron presto en el seno de rica nebulosa en el Norte continental, proclamaron su decisión de unirse para el progreso, y la prosperidad, y fijaron su voto en un documento histórico famoso, ctryo preámbulo habla a los tiempos de esta manera: "Nosotros, el pueblo de los Estados Unidos, a fin de formar una unión más perfecta, establecer la justicia, asegurar la tranquilidad doméstica, proveer a la común defensa, fomentar el bienestar y afianzar las bendiciones de la libertad para nosotros y para nuestra posteridad, creamos e instituimos esta constitución para los Estados Unidos de América."

Estas expresiones, victoriosas del tiempo, prefiguran un programa que podría hacer suyo la americanidad entendida como hoy se entiende (ni recelosa ni resentida); concretan un anticipo del estatuto, del libre concordato que podrían trazarse, si la voluntad les auxilia y los obstáculos no les desaniman ni los dispersan, los pueblos todos del continente, programa distinto ética y políticamente a los de violencia, predominio y opresión sobre los cuales pretenden edificar una parodia de mundo nuevo regímenes e ideologías irreconciliables con la libertad, y distinto, asimismo, de las normas disecadas e insubsistentes, pero conservadas por una ficción temerosa por rutinas estatales intangibles, de otras formas de gobierno de la exhausta Europa que no debemos repetir. Un programa que fué posible y benéfico para cuarenta y ocho repúblicas - tales los Estados de la confederación norteamericana- ¿ ¿no podría serlo también, semejante, para otras veinte repúblicas, sin quiebra de su soberanía ni de sus inalienables e insobornables esencias, traducido pero asimilado virtual 
y sustancialmente, no a la manera romántica de los ingenuos calcos de la propia constitución y sus métodos, hecho por los próceres abuelos con tan acerbos y contrarios resultados, y, ahora, con una madurez mayor que permite el juicio y garantiza la práctica leal?

Si han sido posibles en la tierra un imperio romano, una catolicidad operante en siglos de barbarie, un imperio español bajo el mandato de las leyes de Indias, una asociación de naciones británicas, una federación norteamericana, ¿ por qué no podría serlo una América unida en el condominio de libertades, deberes, derechos y riqueza, integral realización del pensamiento, postergado pero no olvidado, de Simón Bolívar?

Por lo menos, la existencia triunfante de un pacto cual el norteamericano, es un precedente alentador e impresionante cuando se busca en América misma la forma que ha de moldear la armonía en la convivencia, en el progreso, en la justicia, en el bienestar, en la seguridad y la libertad. ¿Utopía? Alejarse de tan razonable precedente por huir de quiméricos riesgos o alardear de iniciativas novedosas -mientras Europa torne a darnos sus plantillas y consejos--, será abocarse a un peligro más agudo: permitir que medren y se expandan los nacionalismos minúsculos, que se acentúen los rasgos diferenciales a costa de los fundamentales rasgos comunes, de parroquia a parroquia, y que germinen más o menos lentamente los odios, las envidias, las rivalidades y otras protervas pasiones que tienen su asiento en el humus de las patrias provincianas sin aspiración de universalidad, o que la han perdido subyugadas por regímenes de dos dedos de frente, como en la dolorosa Europa que debemos empeñarnos en no repetir.

Hay, quiérase o no, concédase o niéguese, una realidad americana que tiende a ser, en sus balbuceos, una conciencia americana; se expresa en mil formas, pide forma de mil maneras, algunas angustiosas; se delinea, pero débilmente y sujeta a azares prodigiosos, en las conferencias interamericanas: iqué día de luz para la humanidad, qué verdadero redescubrimiento, o recreación de América, aquel en que veintitantos pueblos, como en la aurora de la declaración de los derechos del hombre, votaran frente al futuro st decisión inquebrantable de perfeccionar su unidad por un documento indestructible, que derivaría esta calidad del hacerse de inmediato carne y sangre de los pueblos! 
La literatura americana en sus libros, en su periodismo, en sus cátedras y tribunas, sin desvirtuar, bastardear o torcer sus finalidades absolutas de arte, sin entregarse a encender nuevas hogueras de ambición, sin dar pábulo a más recelos ni perderse en obcecados laberintos de amor propio, tiene ahí una empresa magnífica a que servir sobre la confusión de las horas actuales: apagando polémica y garrulería, prejuicio e indiferencia, soberbia e incomprensión, el literato americano hará el bien potenciando las fuerzas de su América - de cada patria pero en relación a la patria magna que será el continente- y encaminándolas al cauce de la unidad y la armonía para el triunfo de la libertad y el logro de la prosperidad común, pero sin olvidarse de proclamar, y de cumplirlo preferentemente en su obra, el consejo, la advertencia, la admonición: No repitamos a Europa, americanos. No repitamos a Europa en nada que separe, en nada que aborrezca, en nada que odie y ensangriente, que lo demás es patrimonio de la humanidad, conquista del espíritu, que debemos ensanchar sin otra medida que el límite de nuestra fuerza y de nuestra ilusión. Y no olvidemos ni un momento en nuestra vida que América es vaso de elección para las llameantes esencias del Espíritu!

César Brañas, Guatemala. 